\title{
From the Perspective of Blended Teaching: The Application of Fragmented Learning in the Class of Bilingual Teaching
}

\author{
Jin Wang, Guangchun Chen, Bo Li \\ Faculty of Economic and Management, Guangdong Polytechnic College, Zhaoqing, China \\ Email: 2559888177@qq.com
}

How to cite this paper: Wang, J., Chen, G. C., \& Li, B. (2020). From the Perspective of Blended Teaching: The Application of Fragmented Learning in the Class of Bilingual Teaching. Creative Education, 11, 2213-2217.

https://doi.org/10.4236/ce.2020.1111161

Received: September 23, 2020

Accepted: November 9, 2020

Published: November 12, 2020

Copyright $\odot 2020$ by author(s) and Scientific Research Publishing Inc. This work is licensed under the Creative Commons Attribution International License (CC BY 4.0).

http://creativecommons.org/licenses/by/4.0/

\begin{abstract}
The purpose of this paper targets how to apply the pattern of fragmented learning (PFL) in the teaching process at the traditional class. This is because personal learning of way cannot be correctly taught and guided by the teacher in the class. Task-based learning (TBL) which combines with the pattern of fragmented learning (PFL) may be an effective teaching approach of bilingual lesson in the class. Therefore, the selection of fragmented learning materials should be hierarchical and continuity. And this guiding path can be applied in the class and will make it easy to gain knowledge for language learners.
\end{abstract}

\section{Keywords}

Fragmented Learning, Blended Learning, Teaching Effect

\section{The Implication Characteristics of Fragmented Learning}

In academic field at present, there is no accurate definition of "fragmented learning", which indicates a kind of informal learning, such as intermittent learning time and diversified learning media. Fragmented learning as personal learning method refers to the fragmented learning acquisition that learners take advantage of modern intelligent terminal devices in flexible time. Arzu Ekoç (2020) analyzed that technology has led to new ways of learning and socializing. This is because teaching is not a solitary act, and teaching activities need the teachers using the network to make an instructional design to be complete in the class. Thus, based on the various situation and fragmented learning it has not the same instructional method. 


\section{The Fragmented Learning of Advantage and Disadvantage in the Class}

Fragmented learning has advantages and disadvantages. Its advantage has accurate studying targeted. Students can choose their learning content according to their situation, which is more suitable for different students' individual learning needs. It needs to be pointed out that this way cannot be correctly guided students in the class, and students' learning quality will be affected and even affecting their learning plan of the curriculum. According to some scholars' research shows that language learning depends on the communicative approach as an important teaching method, which is used in the class (Hymes, 1979, Zhu, Chen, \& Jia, 2019). Besides, the advantage of fragmented learning not only to enriches teaching resource, but this method also improves teaching quality in the class. At the same time, fragmented learning has "a flexible characteristic and pertinence to students learning" (Xiao, 2016). This is because, related short knowledge content can increase students' learning interesting, such as a clear short of video or example of a story.

It worthy noted that fragmented learning has some deficiency in the class where it belongs to shallowed learning. Due to the fragmentation of knowledge only focus on the basic ability of understanding to knowledge, and the lack of guidance for students to have in-depth understanding leads to the divergent thinking of students in the learning process and the lack of holistic thinking. Meanwhile, the majority of students do not keep their attention over 20 minutes in the traditional class (Guli, 2017, Shi, Wang, \& Xu, 2020), because many fragmented pieces of knowledge within the learning content lead to students losing their attention in the class. From the above, it can be seen that the fragmented learning mode has its unique advantages but it also has issues that need to be improved on the method of the teaching process in the class.

\section{TBL Combine with PFL Make a Learning Hierarchical Content to Students}

Traditional teaching approach has not to satisfy in the bilingual teaching class today. In the teaching process, the teachers should base on the practice of teaching first and expositive teaching as the second. The pattern of fragmented learning (PFL) combines task-based learning (TBL) within the teaching process can improve the quality of bilingual learning for students. Students have not the same basics ability of language learning in the class, which often makes it difficult for teachers to give consideration to the different learning ability of students and to satisfy the bilingual learning needs for students in the teaching process. In this case, these fragmented learning of materials of bilingual can be made to hierarchical and it will able to drive students towards passive learning to active learning. According to a study shows if a teacher uses the pattern of fragmented learning within the teaching process of some basic discipline and applied discip- 
line, the teachers must provide a clear explaining and guidance for students in the class (Huang \& Huang, 2016). For the reason, there is not continuity of fragmented learning knowledge of content and make difficult understanding for students. Thus the knowledge of fragmented learning materials should be considered by the teacher in the teaching process, whether or not these learning materials benefit to these different learning basics of students for learning (Liang et al., 2018; Qinjuan \& Ning, 2018). From the above mentioned, TBL combines with PFL can instruct students from shallow understanding to deep learning in the class.

\section{TBL Combine with PFL to Be an Effective Teaching Approach of the Lesson}

The pattern of fragmented learning indeed facilitated students 'learning of language to students at spare time, but from the view of the overall curriculum, the teaching objective is affected, because fragmented learning has a certain dispersion of weakness to affect learners. However, according to Carless (2002) research showed that through combine learning objective with the resource of some short video as a task question to students, which facilitate knowledge exploring awareness to students. Thus, some education scholars evidenced (Gavriushenko, Karjalainen, \& Kankaanranta, 2015) that it does not matter what teaching resource to use in the teaching process, and the significant is that these teaching resources should be organized to reflect systematicness and successional pattern in the bilingual teaching process. Meanwhile, the scholar of J. Willis (1996) demonstrated that a task learning as an activity "where the target language is used by the learner for a communicative goal in order to achieve an outcome". Thus, some linguistic researchers illustrated that tasks, functions and task techniques do not only increase students interesting and attention, but this also enhances the comprehension ability of students to learning objectives in the class. From the above, these studying, task-based learning (TBL) with the pattern of fragmented learning (PFL) can be an effective teaching approach of the lesson in the class. Therefore, it is necessary for teachers to effectively combine TBL systematic learning methods with PFL to maintain a good language learning atmosphere and dynamic to students in the class.

\section{Conclusion}

All in all, with the incessant update of teaching method, the traditional teaching method has not satisfied bilingual teaching today, this is because it is the new media era, the related teaching technology, and fragmented learning materials constantly appear in students' learning activities. It needs to be pointed out that the application of fragmented learning mode in bilingual teaching should serve classroom teaching. Only by systematized and multi-level fragmented learning centering on classroom teaching can the integrated benefits of in-class and out-of-class learning be achieved, and the advantages can be truly enhanced and 
the vitality of the fragmented learning can be fully revitalized. For these reasons, these fragmented learning materials should be hierarchically org the same time, in or anized to apply in the class, instead of learning by students themselves. In order to achieve scientific teaching method to improve learning quality of students, teachers can combine the pattern of fragmented learning (PFL) with the approach of task-based learning (TBL) to create effective blended teaching methods in the class. The last one but it is significant thinking, the research illustrated how to use the pattern of fragmented learning in the teaching process of language in this thesis. However, how to combine PFL with TBL approach is used for the different levels of bilingual teaching class, which needs to be analyzed in the future.

\section{Foundation Item}

Education and Teaching Reform Project by Guangdong Polytechnic College, 2020: "Research on the adaptability of new liberal arts students to theoretical Classroom Teaching under blending teaching mode in Guangdong private Colleges".

\section{Project}

Project No. JXGG202047; the research phased outcomes.

\section{Conflicts of Interest}

The authors declare no conflicts of interest regarding the publication of this paper.

\section{References}

Ekoç, A. (2020). No Teacher Is an Island: Technology-Assisted Personal Learning Network (PLN) among English Language Teachers in Turkey. Interactive Learning Environments, 3, 1-17. https://doi.org/10.1080/10494820.2020.1712428

Carless, D. (2002). Implementing Task-Based Learning with Young Learners. ELT Journal, 56, 389-396. https://doi.org/10.1093/elt/56.4.389

Shi, D. Q., Wang, T., Xing, H., \& Xu, H. (2020). A Learning Path Recommendation Model Based on a Multidimensional Knowledge Graph Framework for E-Learning. Knowledge-Based Systems, 195, Article ID 105618. https://doi.org/10.1016/j.knosys.2020.105618

Gavriushenko, M., Karilainen, L., \& Kankaanranta, M. (2015). Adaptive Systems as Enablers of Feedback in English Language Learning Game-Based Environments. 2015 IEEE Frontiers in Education Conference (FIE), El Paso, TX, 1-8. https://doi.org/10.1109/FIE.2015.7344107

Guli (2017). How to Improve Primary Students Attention in the Class. Education Science No. 8, 192.

Huang, X., \& Huang, X. (2016). Analysis of the Application of Fragmented Learning in the Liberal Arts Students Information Literacy Training. 2016 5th International Conference on Social Science, Education and Humanities Research, Amsterdam: Atlantis Press. https://doi.org/10.2991/ssehr-16.2016.161 
Hymes, D. H. (1979). On Communicative Competence. In J. B. Pride, \& Holmes, Eds., Socio-Linguistics: Selected Reading (pp. 269-293). London: Penguin Books.

Zhu, J., Chen, P., \& Jia, W. J. (2019). Advantages and Disadvantages of Fragmented Learning and Recommendations. Asian Agricultural Research, 11, 87-88+92+89.

Liang, K., Wang, C., Zhang, Y., \& Zou, W. (2018). Knowledge Aggregation and Intelligent Guidance for Fragmented Learning. Procedia Computer Science, 131, 656-664. https://doi.org/10.1016/j.procs.2018.04.309

Qinjuan, Z., \& Ning, L. (2018). The Application of Fragmented Learning in English Listening Teaching on the Network Teaching Platform: Taking Guilin Normal College as an Example. Journal of Guilin Normal College, 32, 135-138.

Xiao, X. M. (2016). 4Gera the Method of Fermented Learning with English Teaching Studying, Technology, No. 17, 280. 